\title{
The NSERC Program of University Research Fellowships
}

\author{
ROBERT J. KAVANAGH*
}

\begin{abstract}
In the mid-1970s several analyses warned of an impending crisis in Canadian universities resulting from the age distribution of faculty members and anticipated trends in student enrolments. It was feared that many young Canadians with new doctoral degrees would be unable to enter academic careers and that the universities would suffer from a lack of young research-oriented faculty members. This paper describes the University Research Fellowships program which was introduced by the Natural Sciences and Engineering Research Council in 1980 as a response to this situation. The steps leading up to the launching of the program, the experience with this program to date, and its impact upon the universities are described. Finally, the Council's plans for the future of this program are discussed.
\end{abstract}

\section{RÉSUMÉ}

Au cours des années 70 , plusieurs analyses présageaient une crise imminente dans les universités canadiennes. Cette crise résulterait de la répartition par âge des membres du corps professoral et des tendances prévues du nombre d'étudiants. On craignait que beaucoup de jeunes Canadiens ayant récemment obtenu leur doctorat ne puissent faire carrière dans une université canadienne. Par ailleurs, les universités subiraient les effets d'un manque de jeunes professeurs désirant faire de la recherche. Cet article décrit le programme de chercheurs-boursiers universitaires qui a été crée par le Conseil de recherches en sciences naturelles et en génie en 1980 pour remédier à cette situation. On y décrit les étapes menant au lancement du programme, les résultats de ce programme jusqu'à présent et ses répercussions sur les universités. Enfin, l'article décrit les projets d'avenir du Conseil en ce qui a trait à ce programme.

Note: This is an abbreviated version of a paper presented at the Annual Conference of the Canadian Society for the Study of Higher Education, Hamilton, Ontario, June 1, 1987.

*Director (Scholarships and Fellowships Programs) Natural Sciences and Engineering Research Council. 


\section{The Genesis of the Program}

Shortly after the conclusion of the second world war, the birth rate in Canada increased to an unusually high level. This situation persisted until about 1965 when a major decline in birth rates commenced. This "baby boom" followed by a "baby bust" had very significant ramifications for Canadian society. In the realm of education a great expansion of the school system was a necessity. This was followed inexorably by a requirement for a dramatic expansion in the university system. New universities sprouted and existing universities expanded rapidly. A natural consequence of these developments was a requirement for many more persons to teach in the universities. The demand for faculty members was not easily met. Canadian universities were not themselves producing adequate numbers of suitable persons with graduate degrees. They were forced to hire large numbers of young individuals who were not always properly qualified and they recruited many persons from other countries. In 1968-69, 40\% of the full-time university teachers were less than 35 years old.

In due course, however, the products of the baby boom passed through the primary schools and a surplus of schools began to exist. The slump in numbers of students progressed year by year through the educational system. By the middle 1970 s, those concerned with the state of the university system were warning that this slump would begin to affect university enrolments by about 1982 . What made the planners particularly worried was the fact that, while university enrolments were likely to fall substantially from about 1982 until about 1995, the large numbers of young faculty members recruited by the universities in the 1960s would, by then, be middle-aged. Thus, the universities would have too many professors and, furthermore, an unduly large fraction of them would be past their prime but not yet ready to retire. The professoriate would be dominantly middle-aged, there would be relatively few retirements, and there would be few opportunities for promising young persons to enter the academic profession. Meanwhile, many of the products of the baby boom would, by that time, have completed their doctoral degrees and would be vainly seeking academic posts which were no longer available.

The increasing awareness of the impending crisis in the universities caused national organizations such as the Association of Universities and Colleges of Canada, the Science Council of Canada, and the National Research Council of Canada, as well as the universities themselves to study the problem in detail with a view to proposing new policies or programs which might alleviate the negative consequences of this situation. The Science Council of Canada played a leading role in these deliberations. An important event in June 1977 was the convening by the Science Council and the AUCC of a Workshop on Optimization of Age Distribution in University Research. One of the outcomes of that workshop was a recommendation for the development of a "para-university research force".

The concept of a so-called para-university research force had been proposed in a key background paper prepared for the workshop by the National Research 
Council of Canada (Derikx, 1977). This paper examined the effect of the aging of the professoriate upon the scientific research capability of the universities. The distorted age structure of the professoriate in the sciences and engineering was seen to have several negative consequences including declining research productivity and a lack of opportunities for creative young researchers to enter the university research force. The paper suggested that one way in which the current distorted age distribution of the faculty could be converted into a more nearly optimum distribution would be to create a special para-university research force consisting of substantial numbers of young researchers who would be awarded fellowships or research associateships by the Council. These researchers would, in due course, be transferred to regular faculty positions as retirements occurred.

The idea of a para-university research force was subsequently taken up by the newly-created Natural Sciences and Engineering Research Council (NSERC) in 1978. In the course of the consultations with the academic community which preceded the development of NSERC's first five-year plan, it became clear that there was strong support for a new program of this nature.

\section{Development of the University Research Fellowships Program}

The Natural Sciences and Engineering Research Council submitted its first five-year plan to the federal government in early 1979. The plan addressed a variety of issues which the Council considered to be of great importance in the context of the need to increase Canada's research and development activities. One of these issues was the need for sufficient highly qualified research personnel. The Council proposed to address this need by greatly expanding its expenditures on scholarships and fellowships and by introducing certain new programs. One of these was a program of University Research Associateships.

The proposed new program was described, in outline, in the five-year plan as follows:

A new and prestigious program of University Research Associates would involve awards to outstanding young researchers with at least two years of postdoctoral experience. The term of these awards would be three years with renewal for up to 2 further years and the possibility of a second-five year award for up to $50 \%$ of the recipients. The successful applicants would have to hold all university privileges of an assistant professor (except full tenure) and would be eligible to apply for NSERC research grants. Most of their time would be devoted to research and development. This program has two objectives: to retain a strong base of excellent research within the university community and to retain some of those researchers as the nucleus of the new generation of Canadian professors that will be required in the 1990's.

The scale of the proposed program was ambitious. It was envisaged that, beginning in 1980-81, 100 new awards would be given each year until 1994-95. Allowing for the possibility of some renewals after the first five-year term, the total number of awards held was projected to increase from 100 in 1980-81 to a maximum of 875 in 1994-95 and then dropping in subsequent years. Based upon 
an assumed salary cost of $\$ 18,000$ per year, the annual cost of the program (excluding the cost of research grants held by Associates) was projected to rise to $\$ 15.7$ million (in 1979 dollars) in 1994-95.

In November 1979, the federal government announced a funding increase for NSERC. While this increase was insufficient to implement all of the proposals contained in the five-year plan, the Council decided to implement a scaled-down version of the proposed program of Associateships. The Council created a Manpower Task Force which was charged with recommending detailed regulations and application procedures for the University Research Associateships. After consultations with the academic community, provincial higher education officials, and certain professional associations, the Task Force presented its recommendations to NSERC in April 1980. Among these recommendations was one to change the name of the proposed program to University Research Fellowships (chercheursboursiers universitaires). The Council accepted the recommendations and announced the new program in May 1980, inviting nominations of candidates for the new awards by a deadline of July 1, 1980. Despite the very short time available to the universities for identifying suitable candidates and assembling the nomination documents, NSERC received 366 nominations involving 345 individuals. The selection committee recommended awards to 100 of these nominees and 94 of these took up their fellowships by the end of 1980 .

\section{The Nature of the Program and its Evolution}

The objective of the University Research Fellowships (URF) program, as described in the May 1980 program description, was to expand career opportunities for a select number of very promising researchers in the natural sciences and engineering. There were two sub-objectives: to assist in maintaining the level of the university research and development effort in Canada; and to assist in maintaining an adequate supply of promising and highly qualified researchers in Canadian universities to help meet the demand for new faculty appointments which was expected to expand rapidly in the early 1990s. Finally, the hope was expressed that this program (and a similar NSERC industrial sector program of Industrial Research Fellowships) would encourage closer interaction between researchers in the universities and in industry and mobility between these two sectors.

In accordance with these objectives, the design of the program was conceived so as to ensure, as far as possible, that only the most promising researchers with relatively recent doctoral degrees would receive fellowships. Fellowships would be tenable in Canadian universities for up to five years in the first instance. During this period, fellows would be expected to devote most of their time to research. The universities were expected to give the fellow a status equivalent to that of faculty member. It was hoped that most fellows would eventually obtain regular faculty appointments at Canadian universities or research positions in the Canadian industrial or government sectors. The presence of the fellows in 
Canadian universities was expected to enable the universities to intensify their research capabilities in fields of high priority.

Full details concerning the program regulations and procedures are contained in NSERC's Scholarships and Fellowships Guide and in its Guide for Fellows and University Administrators. Some of the salient features are outlined in the following paragraphs.

Candidates for fellowships are nominated by universities and may not apply directly to NSERC. Nominees must hold a doctoral degree in an appropriate field and should have had relevant experience following receipt of that degree to the extent normally required by the university for appointment as an assistant professor in the same field. Preference is given to nominees who have not had more than five years of experience after receipt of their doctorate. Fellowships are tenable in science and engineering departments of any Canadian university which is eligible for NSERC support. Fellows are employees of the university and are expected to receive salaries and privileges in accordance with the university's regular policies for faculty members. NSERC contributes a maximum of $\$ 30,500$ per annum towards the cost of a fellow's salary and fringe benefits. The university must contribute at least $\$ 4,000$ per annum. Initial appointments are for three years and renewal beyond that period is subject to a progress review.

It is expected that fellows will spend most of their time on research activities. The necessity for the fellow to establish a program of independent research is considered to be very important. It is recognized that the undertaking of limited teaching duties could be beneficial. Accordingly, fellows are permitted to teach up to the equivalent of one full course per year. Upon taking up an appointment, each fellow is provided with a research grant by NSERC for a three-year period. The levels of these grants have been increased over the years and the current values are $\$ 12,000$ per year for mathematics and statistics and $\$ 15,000$ per year for all other disciplines. In addition, if a fellow wishes to request an operating grant which is bigger than these specified basic grants, the request is reviewed by the appropriate NSERC grant selection committee which may recommend a supplement to the basic grant. After the initial three-year period, fellows must apply to NSERC in the same manner as their regular faculty colleagues for operating grants. Fellows are eligible, at all times, to apply to NSERC for grants through other programs such as those for equipment grants, strategic grants, etc.

The process by which fellows are nominated by the universities and selected by NSERC has evolved somewhat since 1980 . Nomination of fellows initially involved the submission of letters of recommendation, information from the university about the relevance of the fellow's research to the university's research objectives, the availability of space and facilities, the anticipated cost of the fellow's research program including the contribution to be made by the university, and the proposed employment contract, together with personal data about the candidate and the candidate's research proposal. The university was asked to give a priority ranking in the event that more than one nomination was submitted. The 
chief deficiency in this process was in obtaining truly independent assessments of the nominee's calibre and potential as a researcher. Consequently, NSERC now has in place mechanisms which normally result in at least three reports from independent referees. The requirement for universities to submit priority rankings was dropped because of NSERC's view that the excellence of the nominee was the predominant factor to be taken into account by the selection committee. Some universities placed relatively weak candidates high in their priority lists because of internal factors. While this action was understandable, it was not consistent with the wish of NSERC that these fellowships be awarded only to the very best candidates.

The selection process is carried out by the University Research Fellowships Selection Committee. This is an interdisciplinary committee which currently consists of eleven persons chosen for their own research ability as well as their familiarity with other NSERC grants and scholarships programs. In arriving at its recommendations, the committee takes into account the nominee's research record and research proposal, the case made by the sponsoring university, the probability of the nominee being able to establish a viable research program at the university, and the reports received from referees. In some instances, an individual may be nominated by more than one university. In such cases, the committee can recommend approval of one nomination but not of another if it feels that a particular university's argument or the proposed research environment at that university are inadequate.

The third-year progress review involves a thorough assessment of the fellow's accomplishments by the university and by NSERC. The university is asked to take appropriate internal steps to review the fellow's progress and to submit a completed questionnaire to NSERC. That questionnaire seeks information about the fellow's accomplishments during the first two years of the appointment. It also asks the university to provide information about the fellow's appointment: what salary has been paid; what support for the fellow's research has been provided by the university and other sources; what teaching has been done; what opportunities there have been for the fellow to apply for tenure-track positions in the department, among other matters. Finally, it asks the university for a recommendation concerning the suitability of a two-year renewal of the fellowship. In addition to receiving this questionnaire from the university, NSERC requires the fellow to submit a new application for research funding to cover the next two years and up-to-date personal data information.

Unlike the original selection process, the review process involves, not only the NSERC URF Selection Committee, but also the appropriate NSERC Grant Selection Committee. The latter are discipline committees whose members are chosen for their expertise in a particular research field. The Grant Selection Committee is asked to review and report on the fellow's new application for a research grant and on his/her research progress. The use of external referee reports is involved in this process. When the URF Selection Committee subsequently meets it has available the reports and recommendations from the Grant Selection 
TABLE 1

University Research Fellowships, Nominations and Awards 1980-87

\begin{tabular}{|c|c|c|c|c|c|c|c|c|c|}
\hline & 1980 & 1981 & 1982 & 1983 & 1984 & 1985 & 1986 & 1987 & Tota1 \\
\hline Nominations & 366 & 323 & 274 & 284 & 259 & 232 & 222 & 245 & 2205 \\
\hline Nominees & 345 & 288 & 232 & 257 & 217 & 198 & 184 & 201 & 1922 \\
\hline Awards offered & 100 & 75 & 62 & 57 & 62 & 57 & 49 & 45 & 507 \\
\hline Awards Held & 94 & 66 & 50 & 54 & 52 & 52 & 44 & 40 & 452 \\
\hline
\end{tabular}

Committees as well as the university questionnaires. The URF Selection Committee makes its recommendations taking into account all of this information as well as its own assessment of the fellow's research record and research grant application. It may recommend renewal for two more years, termination of the fellowship, or a one-year renewal with the requirement of a further review during the fellow's fourth year.

In view of the reasons why this program was introduced, one of the program regulations specifies that persons already holding tenure-track or tenured positions at Canadian universities may not be nominated for fellowships. While not stated explicitly in NSERC's literature, there was an implicit expectation that, when appointed, fellows would hold term appointments and not be in tenure-track positions. The lack of an explicit statement by NSERC about this matter caused some misunderstanding within the universities. The NSERC Research Manpower Task Force considered this matter as well as the possibility of second-term fellowships (i.e. after the first five years) in June 1983. It recommended certain new regulations relating to these questions. Before implementing these recommendations, NSERC sent a copy of the recommendations to all university presidents and asked for their comments. The majority of the responses were favourable and, in the fall of 1983, the new regulations were approved by the Council. These regulations, which continue to be in force, are outlined below.

In the first place, if a URF accepts a tenure-track position which commences prior to completion of the first three years of the fellowship, the fellowship will be terminated. Secondly, if a fellow is able to obtain a tenure-track position at a Canadian university commencing immediately following the completion of the first five-year term, the fellow will be given a second five-year term. However, the NSERC contribution to the cost of the fellow's salary and fringe benefits is progressively reduced during the second five-year period. Thirdly, if a fellow obtains a tenure-track position which commences between the end of the third year and the beginning of the fifth year, the fellow will receive a five-year fellowship commencing as of the initiation of the tenure-track position. The NSERC salary and fringe benefits contribution is reduced during the latter years of this new five-year period and terminates at the conclusion of the period. These regulations have had a significant impact upon the integration of fellows into regular university positions. 
TABLE 2

University Research Fellowships Held, by Discipline, 1980-87

\begin{tabular}{|c|c|c|c|c|c|c|c|c|c|}
\hline & 1980 & 1981 & 1982 & 1983 & 1984 & 1985 & 1986 & 1987 & Total \\
\hline Biological Sci. & 24 & 19 & 16 & 20 & 18 & 17 & 8 & 13 & 135 \\
\hline Chemistry & 13 & 5 & 2 & 6 & 7 & 5 & 7 & 3 & 48 \\
\hline Computer Sci. & 1 & 1 & 1 & 0 & 0 & 0 & 1 & 1 & 5 \\
\hline Earth Sci. & 2 & 6 & 4 & 2 & 3 & 3 & 4 & 2 & 26 \\
\hline Engineering & 17 & 10 & 8 & 8 & 8 & 6 & 10 & 7 & 74 \\
\hline Management Sci. & 1 & 0 & 1 & 0 & 0 & 0 & 0 & 0 & 2 \\
\hline Math./Stats. & 12 & 8 & 4 & 3 & 5 & 6 & 4 & 3 & 45 \\
\hline Physics/Astron. & 16 & 11 & 11 & 9 & 8 & 9 & 8 & 8 & 80 \\
\hline Psychology & 8 & 6 & 3 & 6 & 3 & 6 & 2 & 3 & 37 \\
\hline TOTALS & 94 & 66 & 50 & 54 & 52 & 52 & 44 & 40 & 452 \\
\hline
\end{tabular}

\section{Statistical Information}

Eight competitions for University Research Fellowships have been held to date. The 1980, 1981 and 1982 groups have completed their first five-year terms. The numbers of nominations, nominees, offers of fellowships, and awards held are shown in Table 1 for each of the 8 competitions. It should be noted that some individuals have been nominated by more than one university. Hence, the number of nominations exceeds the number of nominees. Table 2 shows the breakdown of the awards held by the discipline of the nominating department. The distribution of URFs by university is shown in Table 3 . These figures pertain to the university of initial appointment and do not take into account subsequent movements of fellows from one university to another. Table 4 gives the numbers of persons accepting fellowships who were outside Canada at the time of nomination. The employment status of all fellows appointed to date is shown in Table 5. For the 3 groups which have completed their first five-year term, Table 6 shows the status of the fellows by discipline. Table 7 shows which universities have appointed the 169 fellows who have been successful in obtaining tenure-track positions. It should be noted that a few of these fellows have subsequently changed location. This table does not take such changes into account. It is of interest to note that 113 of these 169 fellows, i.e. $67 \%$, received tenure-track appointments at the universities which originally hosted them as first-term fellows.

\section{Successes and Problems}

A proper evaluation of the URF program could only be obtained after a thorough analysis of the impact of the program by independent assessors. At this particular time, such an analysis would probably be premature. Meanwhile, this section of the paper offers some data and comments from the standpoint of the administrators of the program.

It is appropriate, first of all, to try to determine whether the objectives of the program have been met. Table 5 shows that, to date, 452 individuals have accepted 
TABLE 3

University Research Fellowships Held, by University, 1980-87

\begin{tabular}{|c|c|c|c|c|c|c|c|c|c|}
\hline University & 1980 & 1981 & 1982 & 1983 & 1984 & 1985 & 1986 & 1987 & Total \\
\hline British Columbia & 4 & 3 & 1 & 5 & 2 & 7 & 3 & 4 & 29 \\
\hline Simon Eraser & 3 & 1 & 2 & 1 & 1 & 1 & 2 & 0 & 11 \\
\hline Victoria & 1 & 1 & 0 & 2 & 3 & 0 & 0 & 0 & 7 \\
\hline Alberta & 6 & 3 & 1 & 2 & 3 & 1 & 1 & 3 & 20 \\
\hline Calgary & 4 & 3 & 1 & 3 & 1 & 3 & 1 & 2 & 18 \\
\hline Lethbridge & 2 & 0 & 0 & 0 & 0 & 0 & 0 & 0 & 2 \\
\hline Regina & 0 & 0 & 0 & 2 & 0 & 0 & 0 & 0 & 2 \\
\hline Saskatchewan & 2 & 1 & 0 & 2 & 0 & 0 & 0 & 2 & 7 \\
\hline Manitoba & 4 & 3 & 4 & 2 & 2 & 1 & 0 & 1 & 17 \\
\hline Winnipeg & 0 & 0 & 0 & 0 & 0 & 0 & 0 & 1 & 1 \\
\hline Brock & 0 & 1 & 0 & 0 & 0 & 0 & 1 & 0 & 2 \\
\hline Carleton & 3 & 2 & 0 & 1 & 1 & 0 & 1 & 1 & 9 \\
\hline Guelph & 4 & 2 & 2 & 2 & 2 & 2 & 1 & 3 & 18 \\
\hline Laurentian & 1 & 0 & 0 & 0 & 0 & 0 & 0 & 0 & 1 \\
\hline McMaster & 7 & 1 & 2 & 1 & 3 & 2 & 3 & 1 & 20 \\
\hline Ottawa & 1 & 2 & 1 & 2 & 1 & 1 & 2 & 1 & 11 \\
\hline Queen's & 5 & 4 & 2 & 3 & 3 & 3 & 3 & 2 & 25 \\
\hline Toronto & 13 & 13 & 6 & 6 & 9 & 7 & 5 & 4 & 63 \\
\hline Waterloo & 4 & 4 & 5 & 2 & 2 & 4 & 5 & 1 & 27 \\
\hline Western Ontario & 5 & 5 & 1 & 0 & 2 & 0 & 1 & 0 & 14 \\
\hline Wind sor & 1 & 0 & 0 & 0 & 0 & 0 & 1 & 0 & 2 \\
\hline York & 1 & 1 & 2 & 2 & 4 & 3 & 1 & 1 & 15 \\
\hline Concordia & 2 & 0 & 1 & 1 & 2 & 1 & 1 & 1 & 9 \\
\hline Ecole Polytechnique & 3 & 1 & 2 & 2 & 0 & 0 & 1 & 2 & 11 \\
\hline Laval & 1 & 3 & 1 & 0 & 1 & 1 & 3 & 0 & 10 \\
\hline McGill & 6 & 4 & 5 & 3 & 1 & 4 & 3 & 4 & 30 \\
\hline Montréal & 2 & 2 & 6 & 1 & 2 & 3 & 2 & 1 & 19 \\
\hline Québec - IAF & 0 & 0 & 0 & 0 & 1 & 0 & 0 & 0 & 1 \\
\hline Québec - INRS & 0 & 0 & 0 & 1 & 0 & 0 & 0 & 0 & 1 \\
\hline Québec - Montréal & 0 & 0 & 0 & 0 & 0 & 1 & 0 & 0 & 1 \\
\hline Québec - Rimouski & 0 & 0 & 0 & 0 & 0 & 1 & 0 & 0 & 1 \\
\hline Québec - Trois Riv. & 2 & 1 & 0 & 0 & 0 & 0 & 0 & 0 & 3 \\
\hline Sherbrooke & 3 & 0 & 0 & 2 & 2 & 2 & 0 & 1 & 10 \\
\hline Mount Allison & 1 & 0 & 0 & 0 & 0 & 0 & 0 & 0 & 1 \\
\hline New Brunswick & l & 1 & 1 & 1 & 0 & 2 & 1 & 1 & 8 \\
\hline Dalhousie & 1 & 2 & 2 & 3 & 3 & 2 & 1 & 1 & 15 \\
\hline St. F. Xavier & 0 & 0 & 1 & 1 & 0 & 0 & 0 & 0 & 2 \\
\hline St. Mary's & 0 & 1 & 1 & 0 & 0 & 0 & 0 & 0 & 2 \\
\hline Memorial & 1 & 1 & 0 & 1 & 1 & 0 & 1 & 2 & 7 \\
\hline
\end{tabular}

fellowships at Canadian universities. To put this number into perspective, the total number of faculty members in the sciences and engineering who held NSERC operating grants in 1986-87 was just over 6,000. Thus, those who have held fellowships represent around $7 \%$ of the faculty members who are active in research in the NSERC disciplines. The creation of these 452 research faculty positions has certainly contributed to increasing the career opportunities for promising researchers. Although reliable data is not available, examination of faculty lists in 
TABLE 4

Fellows Outside Canada at Time of Nomination 1980 -87

Competition Year

1980

1981

1982

1983

1984

1985

1986

1987
No. Outside Canada

$\%$ of Fellows

16

30

38

39

42

50

43

60

TABLE 5

Employment Status of University Research Fellows, 1980-87

\begin{tabular}{|c|c|c|c|c|c|c|c|c|c|}
\hline & 1980 & 1981 & 1982 & 1983 & 1984 & 1985 & 1986 & 1987 & Total \\
\hline Initial no. of fellows & 94 & 66 & 50 & 54 & 52 & 52 & 44 & 40 & 452 \\
\hline Award terminated by & & & & & & & & & \\
\hline $\begin{array}{l}\text { NSERC } \\
\text { Resigned fellowship - }\end{array}$ & 3 & 5 & 1 & 3 & 3 & 0 & 0 & 0 & 15 \\
\hline location unknown & 2 & 2 & 0 & 0 & 0 & 0 & 0 & 0 & 4 \\
\hline $\begin{array}{l}\text { Accepted employment } \\
\text { abroad }\end{array}$ & 4 & 5 & 3 & 2 & 2 & 0 & 0 & 0 & 16 \\
\hline $\begin{array}{l}\text { Non-university posn. } \\
\text { in Canada }\end{array}$ & 3 & 5 & 4 & 2 & 1 & 1 & 0 & 0 & 16 \\
\hline $\begin{array}{l}\text { Term university posn. } \\
\text { In Canada }\end{array}$ & 9 & 7 & 3 & 0 & 0 & 0 & 0 & 0 & 19 \\
\hline $\begin{array}{l}\text { Unemployed after first- } \\
\text { term award }\end{array}$ & 1 & 0 & 0 & 0 & 0 & 0 & 0 & 0 & 1 \\
\hline $\begin{array}{l}\text { Resigned fellowship to } \\
\text { accept tenure-track } \\
\text { position }\end{array}$ & 9 & 8 & 4 & 2 & 3 & 0 & 0 & 0 & 26 \\
\hline $\begin{array}{l}\text { Second-term award with } \\
\text { tenure-track position }\end{array}$ & 63 & 34 & 35 & 9 & 2 & 0 & 0 & 0 & 143 \\
\hline $\begin{array}{l}\text { Total fellows in } \\
\text { tenure-track position }\end{array}$ & 72 & 42 & 39 & 11 & 5 & 0 & 0 & 0 & 169 \\
\hline $\begin{array}{l}\text { Continuing to hold } \\
\text { first-term award }\end{array}$ & 0 & 0 & 0 & 36 & 41 & 51 & 44 & 40 & 212 \\
\hline
\end{tabular}

university calendars creates the impression that a significant fraction of the assistant professors in NSERC disciplines are NSERC URFs. The "new blood" which maintains the level and vitality of university research has come, to a significant extent, from the URFs. Table 5 also shows that, as of April 1987, 169 fellows have obtained tenure-track positions at Canadian universities. Hence, the pool of URFs is playing an important role in supplying the current demand for new faculty. The pool of first-term fellows (currently numbering 212) is expected to remain roughly constant for the next 3 years and will then start to fall as the program is phased out. (But the persons in the pool change as new ones enter and 
TABLE 6

\begin{tabular}{|c|c|c|c|c|c|c|c|c|}
\hline Discipline & Total & $\begin{array}{c}\text { Univ. } \\
\text { Tenure- } \\
\text { Track } \\
\end{array}$ & $\begin{array}{l}\text { Univ. } \\
\text { Term } \\
\text { Appt. }\end{array}$ & $\begin{array}{c}\text { Other } \\
\text { in } \\
\text { Canada } \\
\end{array}$ & Abroad & $\begin{array}{c}\text { Term. } \\
\text { by } \\
\text { NSERC }\end{array}$ & Unempl. & Unknown \\
\hline Biological Sci. & 60 & 42 & 10 & 2 & 2 & 2 & 1 & 1 \\
\hline Chemistry & 18 & 15 & 0 & 1 & 1 & 1 & 0 & 0 \\
\hline Computer Sci. & 4 & 4 & 0 & 0 & 0 & 0 & 0 & 0 \\
\hline Earth Sci. & 12 & 8 & 0 & 3 & 1 & 0 & 0 & 0 \\
\hline Engineering & 36 & 26 & 0 & 3 & 2 & 3 & 0 & 2 \\
\hline Math./Stats. & 26 & 22 & 3 & 0 & 1 & 0 & 0 & 0 \\
\hline Physics/Astron. & 37 & 23 & 5 & 2 & 3 & 3 & 0 & 1 \\
\hline Psychology & 17 & 12 & 2 & 1 & 2 & 0 & 0 & 0 \\
\hline Totals & 210 & 152 & 20 & 12 & 12 & 9 & 1 & 4 \\
\hline
\end{tabular}

others leave to take up tenure-track positions.) It is anticipated that this pool will continue to help meet the need for new faculty members during the 1990s.

Closer inspection of some of the figures contained in section 4 reveals some interesting aspects of this program's impact. For example, Table 4 shows that, to date, 166 fellows have come back to Canada to take up their awards. Since the inception of the program, 16 fellows have taken up positions abroad. The net gain so far to Canada is 150 fellows. Furthermore, numerous fellows have informed NSERC that, were it not for the program, they would have left the country to accept positions. It is clear, then, that the program has been successful in keeping some of Canada's most talented young researchers in the country and in inducing a substantial number of others to return to Canada from abroad.

Tables 2 and 6 show how the impact of the program has varied according to discipline. By far, the largest number of fellowships has been held in the biological sciences. Physicists (including astronomers) comprise the second largest group. These numbers reflect the fact that the supply of researchers in these fields has, for most sub-disciplines, exceeded the numbers of available university or other vacancies. The proportion of fellows obtaining tenure-track positions has been somewhat lower than average in these fields. On the other hand, the program has had very little impact in computer science. This is not surprising considering the relative dearth of doctoral graduates in this field and the strong demand for them in the university and industrial sectors. In the engineering disciplines, the total number of fellowships held is the third largest. Nevertheless, given the size of the Canadian professoriate in this field, the number of fellows is relatively low. Although this situation has generated some criticism of the URF program within the academic engineering community, the relatively small impact of the program in engineering is not surprising. The fact is that the supply of Canadian engineering doctoral graduates is small. Furthermore, while most science departments in Canadian universities have been reducing or, at best, maintaining their faculty complements, many Faculties of engineering have been expanding. In addition, 
new engineering doctorates can more readily find employment in the industrial sector. In certain engineering disciplines, there are strong incentives to accept positions in the USA. Overall, therefore, the supply-demand situation in engineering is quite different from that in most science disciplines.

When the URF program was introduced, it was anticipated that possibly $50 \%$ of the fellows might be integrated into regular faculty positions by the end of their first five-year term. The early NSERC literature describing this program referred to the possibility that $50 \%$ of the fellows (meaning those who did not obtain regular faculty positions) might be given a second term of five years as a fellow. Subsequently, as described in section 3, the concept of making a tenure-track position a condition for a second term award was introduced. The effect of this policy may be seen from Tables 5 and 6 . Of the 210 fellows receiving awards in 1980, 1981 and 1982, 152 (i.e. $72 \%$ ) obtained tenure-track positions. Judging from comments received from university administrators and fellows, the financial inducement offered by NSERC to universities which appoint fellows to tenuretrack positions has been effective. It has enabled universities to "bridge" an appointment to the anticipated need for a new faculty member within the next few years. The relatively high percentage of fellows who have been successful in obtaining regular faculty positions, and the small number of fellows who have not found long-term employment at the end of their first term award is a pleasing result. Nevertheless, the question must be asked: are these fellows being appointed to tenure-track positions at the expense of other highly qualified researchers who have suitable qualifications but who do not hold URFs? This possibility clearly exists. At least one university has advertised tenure-track positions, inviting applications from URFs only.

Table 3 shows that fellows tend to receive their initial appointments at large research-intensive universities. This fact prompts the question of whether the small universities have derived any benefit from this program. At the time of creation of the program, a number of the smaller universities urged NSERC to create quotas or maxima for the number of fellows held at a given institution. They suggested that, otherwise, the URF program would further accentuate the gap between the research capabilities of the larger and the smaller universities. This suggestion was not accepted by NSERC because of its concern that fellowships should be awarded only to the most promising candidates. After 8 competitions, it is clear that the smaller universities have, indeed, been at a disadvantage in putting forward successful nominees. If one defines a "small" university as one with not more than 4,000 full-time students, there have been some 15 fellows appointed at 9 small universities. On the other hand, there have been 63 fellows appointed at the University of Toronto alone. In responding to the concerns expressed by some small universities, NSERC pointed out that it was likely that some of the fellows appointed at larger universities could not be absorbed by those universities into permanent positions. Consequently, there would be, in effect, a national pool of available fellows located at the bigger universities who would be available to the small universities when tenure-track openings occurred. By appointing fellows to 
TABLE 7

Distribution of Tenure-Track Appointments by University, 1980-1984

\begin{tabular}{|c|c|c|c|c|c|c|}
\hline University & 1980 & 1981 & 1982 & 1983 & 1984 & Total \\
\hline British Columbia & 2 & 2 & 1 & 1 & 0 & 6 \\
\hline Simon Fraser & 3 & 1 & 0 & 1 & 0 & 5 \\
\hline Victoria & 1 & 1 & 0 & 0 & 1 & 3 \\
\hline Alberta & 5 & 1 & 1 & 3 & 1 & 11 \\
\hline Calgary & 3 & 3 & 0 & 1 & 0 & 7 \\
\hline Lethbridge & 2 & 1 & 1 & 0 & 0 & 4 \\
\hline Saskatchewan & 0 & 1 & 0 & 0 & 0 & 1 \\
\hline Brandon & 0 & 1 & 0 & 0 & 0 & I \\
\hline Manitoba & 3 & 3 & 3 & 0 & 1 & 10 \\
\hline Winnipeg & 0 & 1 & 0 & 0 & 0 & 1 \\
\hline Carleton & 3 & 0 & 1 & 1 & 0 & 5 \\
\hline Guelph & 4 & 0 & 1 & 1 & 0 & 6 \\
\hline Lakehead & 0 & 1 & 0 & 0 & 0 & 1 \\
\hline McMaster & 6 & 1 & 2 & 0 & 0 & 9 \\
\hline Dttawa & 1 & 2 & 2 & 0 & 0 & 5 \\
\hline Queen's & 3 & 1 & 1 & 1 & 1 & 7 \\
\hline Toronto & 7 & 5 & 2 & 0 & 1 & 15 \\
\hline Waterloo & 4 & 2 & 4 & 0 & 0 & 10 \\
\hline Western Ontario & 2 & 3 & 2 & 0 & 0 & 7 \\
\hline York & 2 & 0 & 3 & 1 & 0 & 6 \\
\hline Concordia & 1 & 0 & 0 & 0 & 0 & 1 \\
\hline Ecole Polytechnique & 2 & 0 & 1 & 0 & 0 & 3 \\
\hline Laval & 2 & 2 & 1 & 0 & 0 & 5 \\
\hline McGil1 & 5 & 2 & 5 & 1 & 0 & 13 \\
\hline Montréal & 1 & 1 & 3 & 0 & 0 & 5 \\
\hline Québec - Trois-Riv. & 1 & 1 & 0 & 0 & 0 & 2 \\
\hline Sherbrooke & 1 & 0 & 0 & 0 & 0 & 1 \\
\hline Moncton & 0 & 0 & 1 & 0 & 0 & 1 \\
\hline Mount Allison & 1 & 2 & 0 & 0 & 0 & 3 \\
\hline New Brunswick & 2 & 1 & 0 & 0 & 0 & 3 \\
\hline Dalhousie & 1 & 3 & 1 & 0 & 0 & 5 \\
\hline St. F. Xavier & 1 & 0 & 1 & 0 & 0 & 2 \\
\hline St. Mary's & 1 & 0 & 1 & 0 & 0 & 2 \\
\hline Prince Edward Island & 1 & 0 & 0 & 0 & 0 & 1 \\
\hline Memorial & 1 & 0 & 1 & 0 & 0 & 2 \\
\hline
\end{tabular}

these positions, the smaller universities would be acquiring first class individuals who had been through a rigorous multi-stage screening process and who, in all likelihood, would provide research stimulation and leadership. Table 7 shows that 18 fellows have been appointed to tenure-track positions at 10 small universities. Thus, although new fellows appointed at small universities represent only about $3 \%$ of the total, those receiving tenure-track appointments at small universities represent about $11 \%$ of all such appointees. The evidence to date seems to indicate that the smaller universities can benefit from the URF program especially if they make use of the available pool of fellows at larger universities when filling tenure-track vacancies. 
At the time of the progress review undertaken during the third year of the first term, each fellow is invited to write to NSERC, in confidence, about his or her experience as a fellow. Between 60 and $65 \%$ of the fellows have responded to this invitation each year. Their comments have been most helpful in monitoring the program and in identifying potential problems. Some of the more common and significant problems encountered by fellows will be summarized below.

Perhaps the most common problem, especially during the earlier years of the program, was the perception by faculty colleagues that university research fellows were not "real" faculty members but were merely some new form of postdoctoral fellow. This attitude translated, in some cases, to the assignment of inappropriate office space, or the expectation that the fellow would "assist" a faculty member with their research. Although this problem has not entirely disappeared, it is now much less prevalent as the URF program has become better known and understood.

A related problem concerns the availability to the fellow of the normal rights and privileges available to regular faculty members. There have been instances where fellows have been denied access to travel funds, secretarial assistance, and similar benefits available to their colleagues. On occasion, fellows have been forgotten when faculty salary adjustments have been made. In most instances, these problems seem to have occurred because of the attitude of the department chairman rather than because of university policy. Generally speaking, problems tend to occur at large universities where there is less uniformity in departmental policies and less ability to ensure consistency across the university. In such universities, the fellows in one department may be treated very well whereas in another, the fellows are treated as second class faculty.

The academic titles awarded to fellows by their universities have been a cause for concern at some universities. Most institutions appoint their fellows as assistant professors or research assistant professors. Others, however, may confer a title such as adjunct assistant professor. Regrettably, the connotations of such a title are that the fellow is not really a faculty member. This, of course, is contrary to NSERC's intentions. It seems that administrative inertia or faculty associations may be the reason for the reluctance of some universities to award appropriate titles to their fellows.

A problem with potentially serious consequences relates to the university's agreement to provide suitable space and research facilities for the fellow. There have been instances where the fellow arrives to find inadequate office space and that the promised research laboratory has not materialized. One fellow who was promised a laboratory and an office by the department chairman during an interview had to wait for almost 2 years before adequate facilities were provided. The fellow subsequently told NSERC:

I had no reason to disbelieve the Chairman and no reason to suspect that changes would not be implemented quickly by the Faculty to allow my working here. The Department wished to present a positive image of itself, an 
image of renewal, of dynamism. I was seduced and I regret it. I have since warned every URF candidate that I have seen in interviews, and I daresay my comments were heeded.

Fortunately, such instances are not common, but when they do occur, they can have serious consequences for the fellow's research productivity.

A common criticism of the program by URFs themselves is that the fellowship confers no security. Knowing that the fellowship will not be renewed after the first five years unless a tenure-track position is obtained, some fellows are understandably worried about their longer term prospects. The suggestion which they sometimes make to NSERC is that a university should not be permitted to host a fellow unless it is willing to guarantee a tenure-track position at the end of the five-year period. Unfortunately, this suggestion ignores the problems which resulted in the creation of the program in the first place. Present financial pressures and the limited numbers of faculty retirements mean that the universities are very cautious about making new tenure-track appointments and about committing themselves to do so five years in the future. Some universities appoint fellows with the knowledge that there is a reasonable probability of a tenure-track position opening up within the next five years. In such cases, the fellow is encouraged to compete for the vacancy when it occurs and, if their record as a fellow has been good, they stand a good chance of being the successful candidate. This, however, is far from the same as offering a guaranteed tenure-track position when the fellow is first appointed. In practice, it seems that many fellows have been unduly pessimistic about their chances of obtaining a tenure-track position within five years. The success of the 1980,1981 and 1982 fellows in this respect may give some encouragement to subsequent groups.

A practical problem for fellows in some disciplines is that they may devote a great deal of effort to building up a needed experimental facility and may then have to leave it behind if they accept a tenure-track appointment at a different university after five years. There is no easy solution to this problem although NSERC does encourage the original host university to allow the fellow to transfer equipment bought with NSERC grants to the new university.

The supervision of graduate students can create problems for fellows. NSERC encourages fellows to engage in this activity and most universities place no restrictions on the fellows in this respect. The problem arises from the temporary nature of the fellow's appointment and the possibility that the fellow may change universities and have to leave behind one or more students. The problem is especially acute in the case of Ph.D. students. Such students may be unwilling to work with a fellow for fear of losing their supervisor at a critical stage of their thesis research. Where students are willing to take this risk, fellows are confronted with the moral dilemma: should they accept the student, benefit from the student's collaboration, and expose the student to the risk of losing their supervisor, or should they decline to accept the student for the student's own good and thereby give up the opportunity to have a research collaborator? 
The final question to be addressed in attempting to assess the success or otherwise of the URF program is whether any universities have exploited the problem by not adhering to the spirit and objectives of the program. For example, have there been cases in which a university has the funding available to make a tenure-track appointment but chooses, instead, to appoint a first-term URF, thereby receiving substantial NSERC subsidization for the incumbent's salary?

It is not easy to answer this question. A few critics of the program have alleged that such academic games do occur. Details are not forthcoming, however. Certainly a few fellows have reported to NSERC about being told by their department that they will not be considered for a particular tenure-track vacancy for which they would be well-suited. It seems that their departments would prefer to have two faculty members for the price of one rather than have the fellow move into the tenure-track position. One advantage of the trend towards unionization of Canadian faculty members is the rendering much more difficult of such dubious practices.

It seems fair to conclude, on the basis of many communications with fellows, other faculty members, and university administrators, that there have been some instances of misuse of the URF program by universities but that the great majority of departments, faculties and universities are respecting the spirit as well as the letter of the program regulations and objectives.

\section{The Future of the Program}

As proposed in NSERC's first five-year plan, new fellowships were to be awarded until 1994. It was anticipated that significant numbers of tenure-track positions would open up by about that time and that the need for the program would diminish. Thus, it has always been the intention that the URF program would have a finite life.

During the latter half of 1986, NSERC conducted an extensive review of all of its programs. In conjunction with this review, a detailed analysis was undertaken of the demand for new faculty members in the natural sciences and engineering and of the anticipated supply of suitably qualified persons to fill these positions (Kavanagh and de la Mothe, 1986). In so doing, it became apparent that the scenario predicted by studies undertaken in the middle and late 1970s has not occurred exactly as expected.

While the projections of numbers of university-age Canadians have been essentially correct, the assumptions made about the proportion of that group who attend universities (the participation rate) have been too conservative. In 1975, the participation rate for full-time students was $11.57 \%$. The rate dropped to a minimum of $10.71 \%$ in 1979 . Since then, however, the rate has increased monotonically and is now estimated to be about $14.4 \%$. The effect of this significant increase in the participation rate has been to compensate for the decrease in the university-age population. Thus, the total number of full-time students at Canadian universities has risen until now rather than fallen. In addition, 
there has been an increasing trend towards part-time studies. A consequence of these trends has been that the demand for university faculty has risen rather than fallen. The increase in the number of university faculty has been small and the distorted age structure of the professoriate inherited from the 1960s still exists, hence the problems anticipated in the middle 1970s have occurred. However, these problems have not been as severe as had been feared.

The recent NSERC analysis of the demand for new faculty members took into account the expected future size of the university-age population, the participation rate, numbers of international students, student-teacher ratios, the mortality rate of university faculty, the current age distribution of faculty, transfers of faculty into and out of the university sector, and the impact of changes in retirement policies. The analysis estimated that there are about 150 tenure-track vacancies per year in the science and engineering disciplines at present, and that this number would increase to about 220 per year by 1998 . The demand for new faculty is especially strong, and will remain so, in the engineering disciplines. It is much less, proportionately, in the agricultural and biological sciences and in the mathematical and physical sciences. However, the demand in these disciplines will increase noticeably after about 1990 .

A corresponding analysis of the supply of Canadian doctorates available for academic or other employment took into account predicted doctoral enrolments at Canadian universities, the proportion of doctoral candidates who obtain their degrees, the numbers of graduates who are Canadian citizens or permanent residents, the number of Canadians receiving degrees abroad, the fraction of graduates who accept employment abroad and the numbers of international students who are granted permission to remain in Canada and accept employment. The analysis estimates a total of about 650 available doctoral graduates per year at present, increasing gradually to about 780 per year in 1990. The numbers of engineering graduates are forecast to be significantly less, in relation to the faculty population, than for the sciences.

It should be emphasized that this predicted supply of doctorates must meet the demand from not only the academic sector, but also from the industrial and government sectors. If one takes into account qualitative assumptions about the demand from these two sectors, the picture which emerges with respect to faculty recruiting is as follows.

In the agricultural and biological sciences, the universities will have little difficulty in recruiting suitable persons until at least the end of the century except in certain niches relating to biotechnology. In the engineering disciplines, the universities now experience severe difficulties in recruiting faculty in many areas and, unless some extraordinary action is taken, these difficulties will prevail until at least the end of the century. In the mathematical and physical sciences, universities now experience little difficulty in recruiting in some disciplines but significant problems in others (e.g. computing science). The situation is likely to change by the middle 1990s when there will be significant shortages of qualified persons in many fields. 
In the light of these analyses, it seems clear that the continuing need for the URF program is a function of discipline. In engineering, the need is minimal and the real need is for some alternative measures which will increase the number of available doctorates and the ability of the universities to compete effectively for such persons against the industrial sector and employers in the USA. In the agricultural and biological sciences, the URF program can continue to play an important role, for the time being, in keeping highly qualified scientists in research positions in Canada until suitable employment opportunities arise. The same is true in some fields in the mathematical and physical sciences (such as physics). However, bearing in mind the five-year duration of the fellowships and the anticipated rise in tenure-track vacancies by the middle 1990s, it seems appropriate to make no further awards after about 1990.

NSERC's Council has recently made the decision to phase out the URF program in accordance with the above schedule. It is anticipated that 40 new awards will be offered in 1988 and 35 in each of 1989 and 1990. On the basis of this decision, NSERC will have made some 560 awards through this program. The last of the first-term awards will terminate in 1995 and the last of the second-term awards will terminate in the year 2000. Experience to date suggests that around 400 fellows will have found tenure-track positions at Canadian universities through this program by 1995 . By the time the last fellow ends his or her salary support via this program in the year 2000 , the program will have cost about $\$ 100$ million in current dollars over the 20-year life of the program.

It is interesting to note that, at the time when NSERC decided to phase out the URF program, other agencies in Canada are introducing programs with similar objectives. The Social Sciences and Humanities Research Council inaugurated its program of Canada Research Fellowships in 1986, and the Province of Ontario has recently introduced a faculty renewal program.

\section{Conclusions}

Although it is premature to try to arrive at a set of final conclusions about the impact and effectiveness of the University Research Fellowships program, it seems clear that for a substantial number of excellent young research scientists, the program has provided the only means by which they could continue to be active in research and also stay in Canada. It is likely that, by 1995, a large proportion of these fellows will have been integrated into tenure-track positions at Canadian universities. Hence, the program will have influenced the composition of university staff in science and engineering at the junior ranks, at virtually all Canadian institutions. The program is expensive. Each fellow integrated into a tenure-track position will have cost NSERC about a quarter of a million dollars. However, this cost must be compared with the investment of public funds which is lost whenever a research scientist or engineer decides to leave Canada or to abandon research as a career. 
The University Research Fellowships program has been a major effort by NSERC to meet the challenges which have arisen as a result of certain demographic events. It is hoped that this description of NSERC's experiences with the program will be of interest to those involved in academic planning and, in particular, to the universities which have been NSERC's partners in this undertaking.

\section{ACKNOWLEDGEMENTS}

Major contributions to the development of the NSERC University Research Fellowships program and to its subsequent refinement have been made by Arthur Bourns, Teresa Brychcy, Jacques Danis, Gilles Julien, Gordon MacNabb, and Louis Pinaud.

\section{REFERENCES AND BIBLIOGRAPHY}

Auerbach, L. \& Gerber, A. (1976). Implications of the changing age structure of the Canadian population. Perceptions 2. Science Council of Canada, Ottawa.

Bovey, E. C., Mustard, J. F. \& Watts, R. L. (1984). Ontario Universities: Options and Futures. The Commission on the Future Development of the Universities of Ontario, Toronto.

Council of Ontario Universities (1986). Bottoming out. Review 1982-83 to 1985-86, Toronto.

Derikx, A. L. (1977). Background study on age-relevant characteristics of university researchers supported by the National Research Council of Canada. Background papers for a workshop on optimization of age distribution in university research. Science Council of Canada, Ottawa.

Kavanagh, R. J., LeBlanc, E. \& Tremblay, M. (Eds.) (1977). University research manpower: Concerns and remedies. Proceedings of a workshop on the optimization of age distribution in university research. Science Council of Canada, Ottawa.

Kavanagh, R. J. \& de la Mothe, J. (1986). Analysis of demand for and supply of new faculty members and impact of URF program. Internal Report. Natural Sciences and Engineering Research Council, Ottawa.

Natural Sciences and Engineering Research Council of Canada (1979). A five-year plan for the programs of the Natural Sciences and Engineering Research Council, Ottawa.

Natural Sciences and Engineering Research Council of Canada (1986). Scholarships and Fellowships Guide, Ottawa.

Natural Sciences and Engineering Research Council of Canada (1986). The university research fellowship program: a guide for fellows and university administrators, Ottawa.

Science Council of Canada (1979). University research in jeopardy: the threat of declining enrolment. Report no. 31. Ottawa. 